GLUCONEOGENIC AND BRANCH CHAIN AMINO ACID STUDIES IN

450 hypopituITARISM. L. G. Linarelli. Mercy Hospital an Children's Hospital San Diego, Department of Pediatrics, University of California, San Diego.

Gluconeogenic amino acid and branch chain amino acid studies were performed on 8 growth hormone deficient patients without spontaneous hypoglycemia compared to constitutional short children. New information on alanine, glycine, glutamine and leucine was obtained corparing 30 minute response to $S$. Glucagon $30 \mathrm{ug} / \mathrm{kg}$. Comparable fasting and gluconeogenic hypoaminoacidemic responses to Glucagon occurred in all study groups,
i.e., controls, pre-hGH therapy, post-hGH therapy, Anavar, and hGH plus Anavar. However, plasma branch chain amino acid leucine delta $(\Delta)$ absolute reduction in response to Glucagon was enhanced in hGH deficlent children on Anavar alone or in combination with

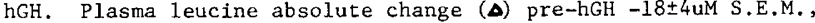
on Anavar $-27 \pm 4$ S.E.M. $(p<0.05)$ and hGH plus Anavar $-34 \pm 3$ S.E.M. $(<0.01)$. Thus branch chain but not gluconeogenic amino acid was affected by the anabolic nature of Anavar and growth hormone. Lower fasting glucose and insulin values with blunted responses to Glucagon were noted in hGH deficient children. Asymptomatic hGH deficient patients falled to show fasting hypoalaninemia or abnormal $(\Delta)$ response to Glucagon, suggesting that hGH deficiency alone does not lead to gluconeogenic substrate-limited disorder. Whereas an additional ketotic hypoglycemic patient studied with both hGH and ACTH deficiency did show blunted hypoalaninemic response to Glucagon, i.e., $\Delta-10 \mu \mathrm{M}$ pre-therapy; $\Delta-20 \mu \mathrm{M}$ on $\mathrm{hGH}$ and $\Delta-130 \mu \mathrm{M}$ on cortisone.

hGH support by the National Hormone and Pituitary Program.

\title{
$\dagger 451$
} TURNER SYNDROME (TS): ULTRASONOGRAPHY (US) DEFINES Mitchell E. Geffner. $\frac{\text { Hooshang }}{\text { UCLA }}$ School of Me dicine, UCLA Medical Center Departments of Pediatrics and Radiology, Los Angeles. Renal anomalies occur with sufficient frequency in Turner Syndrome to warrant routine imaging. Previously using IVP, in 36 of 98 TS patients, we found: significant obstruction with hydronephrosis (3), unilateral renal agenesis (1), horseshoe kidney (6) renal ectopia (3), and minor anomalies of the calyces and collecting system (23). Since introducing ultrasonography, we collecting system (23). Since introducing ultrasonography, we have studied 18 patients, demonstrating the presence of hydrone-
phrosis, horseshoe kidney, ectopia, extrapelvic calyx, and unilateral absence.

Pelvic imaging, considered essential in TS patients with a $Y$ chromosome, had not been otherwise used to define gonadal structures. With US, we have demonstrated, so far, a gonadoblastoma chromosome, whi studied routinely showed no gonadal structures at all. However, in 3 adolescent patients with spontaneous menses and one with spontaneous breast development and normal serum gonadotropins, we found unilateral or bilateral ovarian structures. In 3 other adolescents whose spontaneous menses had ceased 2+ years ago, ovaries were not seen on US. Thus, the presence of ovaries demonstrable with US correlates with active ovarian function.

In summary, ultrasonography can replace IVP in routine renal imaging in TS; it can also assess pelvic anatomy, detect gonadal tumors, and document functioning ovarian tissue.

ARGININE VASOTOCIN PRODUCTION RATES AND METABOLIC 452 CLEARANCE RATE IN THE FETUS, PREGNANT \& NONPREGNANT EWE. Rosemary D. Leake, Max G. Ervin, Hendrik Stegner, Sue M. Palmer, and DeIbert A. Fisher, Depts. Of Peds \& Arginine vasotocin (AVT), a neurohypophyseal peptide (NHP) with antidiuretic and oxytocic actions, is widely distributed in lower vertebrates and has been identified in fetal mammalian $p i-$ tuitary glands by bioassay and RIA methods. To determine whether AVT is present in ovine blood we extracted pooled fetal and maternal plasma using Sep-Pak cartridges and characterized the recovered NHP immunoreactivity (IR) by RIA and high pressure liquid chromatography (HPLC). AVT-IR migrated similarly to synthetic AVT by HPLC. AVP and OT-IR were well separated from the AVT peak.

We measured AVT metabolic clearance rates (MCR) and production rates (PR) in chronically catheterized (124-129 days' gestation) fetal/maternal sheep and in nonpregnant ewes using constant infusion methodology. Three $(5 \mathrm{~m} 1)$ blood samples were obtained over $\mathrm{l} \mathrm{hr}$. and AVT was infused to steady state conditions; blood samples for AVT were obtained at $+30,+40,+50$ and +60 minutes. Results:

\begin{tabular}{|c|c|c|c|}
\hline-1 & $\begin{array}{c}\text { Baseline AVT } \\
(\mathrm{pg} / \mathrm{ml})\end{array}$ & $\begin{array}{c}\mathrm{AvT}-\mathrm{MCR} \\
(\mathrm{ml} / \mathrm{kg} / \mathrm{min})\end{array}$ & $(\mathrm{pg} / \mathrm{min} / \mathrm{kg})$ \\
\hline tu & $1.4 \pm 0.3$ & $5.5 \pm 1.2$ & $7.1 \pm 1.3$ \\
\hline$(0-5)$ & $1.7 \mp 0.3$ & $4.8 \mp 1.4$ & $8.5 \pm 2.2$ \\
\hline ewe $(n=5)$ & $1.1 \pm 0.3$ & $7.6 \pm 1.3$ & $10.8 \pm 2.6$ \\
\hline
\end{tabular}

Thus: 1) AVT is present in ovine fetal and maternal plasma, 2) MCR and PR are similar among ovine fetuses, pregnant and nonpregnant ewes.
GONADOTROPIN-RELEASING HORMONE (GNRH)/THY

453 ROTROPIN-RELEASING HORMONE (TRH) TESTING IN PRECOCIOUS PUBERTY SECONDARY TO HYPOTHALAMIC HAMARTOMA. Barry Marx and Thomas Moshang, Jr. Univ. of Pa. School of Medicine, Children's Hospital of Philadelphia

FSH, LH and prolactin (pro) responses to GNRH/TRH testing do not distinguish patients with idiopathic sexual precocity from those with hypothalamic hamartoma. Post-operative GNRH testing however, may be useful in the follow-up of cases due to organic lesions.

A $29 / 12$ year old white female with breast development, rapid weight gain and linear growth since age 2 years, and pubic hair growth for 2 months was evaluated. Her height and weight were greater than 95th percentile, with Tanner III breast development, Tanner II pubic hair, and estrogenized vaginal mucosa. Brain CAT scan revealed a hypothalamic mass, and a hypothalamic hamartoma was surgically removed. The results of pre- and post-operative ( 6 wks) GNRH/TRH testing are as follows:

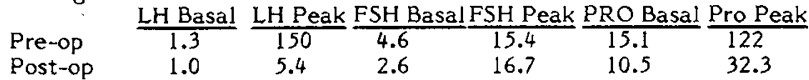

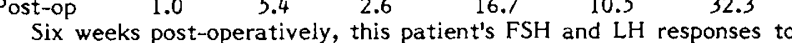
GNRH were returning towards normal, well in advance of any clinical signs. Post-operative GNRH testing may be a useful too in following patients with CNS hamartoma after surgery. The exaggerated prolactin response to TRH has been noted in this clinic in other patients with idiopathic precocious puberty. Hochmann et. al. demonstrated GNRH by immunoflourescence in a hypothalamic hamartoma. Exaggerated PRO responses to TRH may be due to GNRH sensitization of lactotrophs.

454 Kenneth McCormick, Moira Shea. (Spon. by Gilbert B. Forbes). University of Rochester Medical Hyperprolactinemia occasionally can be found in children with primary hypothyroidism, most likely due to TRH stimulation of pituitary lactotrophs. We measured TSH and prolactin levels in 33 blood samples from 8 primary hypo, 2 hyper, and 9 euthyroid full term infants up to 9 months of age. There was a significant correlation between serum TSH and prolactin levels: prolactin $(\mathrm{ng} / \mathrm{m} 1)=31.1+0.7 \mathrm{TSH}(\mu \mathrm{U} / \mathrm{m} 1)[\mathrm{r}=0.84]$. Furthermore, prior to therapy, the hypothyroid babies, all less than 5 weeks of age, had marked elevations $(p<.005)$ in serum prolactin levels compared to age-matched controls. Results are expressed as mean + S.E.M.

\begin{tabular}{lccc}
\hline PATIENTS (n) & AGE (wks) & TSH (NU/m1) & PROLACTIN (ng/m1) \\
\hline Hypothyroid (5) & $2.0 \pm .3$ & $644 \pm 122$ & $474 \pm 113$ \\
Control (6) & $3.7 \pm .8$ & $4.2 \pm .6$ & $27 \pm 11$
\end{tabular}

Prolactin leve1s declined in parallel with TSH levels upon

thyroid replacement.

Since prolactin affects mammalian salt and water metabolism, even in neonates (Ped Res $17: 665,1983$ ), enormous elevations of this hormone may explain in part the edema occasionally observed in congenital hypothyroidism. 455 CORTISOL BINDING GLOBULIN(CBG) IS DECREASED
IN OBESE MALE ADOLESCENTS. George Wm. MOll1,
University of Chicago, Wy ler Children's Hospital, Department of Pediatrics, Chicago, Illinois.

We have measured the concentration of $C B G$ in plasma from adolescents at various stages of pubertal development and assessed the influence of obesity upon plasma CBG levels.

We found that plasma CBG concentrations did not vary significantly with pubertal stage in normal, nonobese male (CBG=250+50 nM [Mean+SD]) or female ( $\mathrm{CBG}=240 \pm 70 \mathrm{nM}$ ) adolescents. In these normal adolescents CBG levels did not significantly ${ }^{c}$. 9 relate with an index of body mass (we1ght/[he1ght] 2.97 ).

We compared the CBG plasma concentrations in obese adolescents with those of our nonobese normals. Among 9 obese males (11-17 y/0,145-246 lbs), 4 had subnormal CBG levels $(75-144 \mathrm{nM}, \mathrm{p}<0.05)$. Among 5 obese female
$(5-18$ y/o, $75-338 \mathrm{lb})$, none had abnormal CBG levels.

We conclude that body mass, sex and pubertal stage do not normally influence $C B G$ levels during adolescence. This contrasts with the recognized influence of these variables upon Testosterone-Estradiol Binding Globulin ( $T$ eBG) concentrations. In the presence of obesity, $C B G$ levels are reduced in males. The normal interrelationships among body mass, $C B G$ and TeBG levels appear to be altered in the presence of obesity in adolescence. 